\title{
Frequency control of future power systems: reviewing and evaluating challenges and new control methods
}

\author{
Zeyad Assi OBAID $^{1}$ (1) Liana M. CIPCIGAN ${ }^{2}$, Lahieb ABRAHIM ${ }^{3}$, \\ Mazin T. MUHSSIN ${ }^{4}$
}

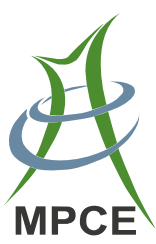

\begin{abstract}
Integration of more renewable energy resources introduces a challenge in frequency control of future power systems. This paper reviews and evaluates the possible challenges and the new control methods of frequency in future power systems. Different types of loads and distributed energy resources (DERs) are reviewed. A model representation of a population of the water heater devices for the demand side frequency response is considered. A model representation of a population of battery energy storage system (BESS)-based DERs such as smart electric vehicles (EVs) charging, large-scale BESSs, and residential and non-residential BESSs, are highlighted. The simplified Great Britain power system and the 14-machine South-East Australian power system were used to demonstrate the
\end{abstract}

CrossCheck date: 8 May 2018

Received: 10 January 2018/Accepted: 8 May 2018/Published online: 28 August 2018

(C) The Author(s) 2018

$\triangle$ Zeyad Assi OBAID

zeyad.a.obaid@gmail.com

Liana M. CIPCIGAN

CipciganLM@cardiff.ac.uk

Lahieb ABRAHIM

lahieb.abrahim@gmail.com

Mazin T. MUHSSIN

mazinthany2004@gmail.com

1 College of Engineering, University of Diyala, Baqouba, Diyala, Iraq

2 Institute of Energy, School of Engineering, Cardiff University, Cardiff, UK

3 School of Engineering, South Wales University, Treforest, Wales, UK

4 College of Engineering, Mustansiriyah University, Baghdad, Iraq effectiveness of the new methods in controlling power system frequency following a disturbance. These new methods are effective in recovering the fallen frequency response and present a great potential in controlling the frequency in future power systems.

Keywords Battery energy storage system (BESS), Distributed energy resource (DER), Electric vehicle, Home-based BESS, Large-scale BESS aggregation, Demand side response, Frequency control, Markov chain

\section{Introduction}

Due to the integration of renewable energy resources (RESs), performing the frequency control from only the conventional generation becomes more expensive. The aggregation of the demand side controllable devices to regulate the frequency is a new method to alleviate the expanding need in the conventional power generators [1-3]. The distributed energy resources (DERs) are becoming more attractive to supply local loads alongside with the conventional generators [1]. The DERs have different power dynamics compared with the classical power generators. Some DERs had no rotational inertia and are connected to the grid via power electronics interface. The whole power system stability with the integration of DERs is an important issue in the modern systems. DERs and their interactions have to be well coordinated. The DERs with a well-coordinated control can significantly improve the stability of the power system frequency [1-3]. The uses of the emergency power amount from the load side for the frequency reserve services presents a new challenge. The challenge is associated with the control of large distributed loads [4]. Especially, with the electric vehicles (EVs), 
Residential battery energy storage systems (BESSs), water heaters, and cloth dryers. Therefore, the DER allocation is also important to enhance the integration of these power sources and improving the power system frequency [4].

The load control with the integration of EVs and distributed generators was presented in [5] for the power regulation. The load-shifting optimisation problem was solved according to technical and market conditions. This approach is applicable for various DERs such as the EVs smart charging [5]. Also, a review of the congestion management methods was presented in [6] for the distribution network with high penetrations of DERs. The methods covered the market and direct control methods. Furthermore, a review of the power electronics-based DERs and their stability problem under the smart grid scenario was proposed in [7]. Some renewable energy sources and intelligent loads were considered as an example of the power electronics-based DERs. The conventional power system and power electronics stability theorems were used to define the potential problems. The stability challenges were identified with the possible solutions from the steady state, small-signal, and large-signal stability criteria [7]. Intelligent electronic devices (IEDs) are the standard protection and control equipment that is being used nowadays in power systems. These smart devices are used for different applications such as system control and protections, hence, can boot the system modelling and analysis of power systems [8].

In the Great Britain power system, the demand side frequency control (DSFC) and BESSs were considered in [9-12]. They are among the DER key factors for the modern power system. BESSs are considered in the previous work for the application of the frequency regulation in the power system $[13,14]$. It presented a fast dynamic response and compensated the load change on the grid side. Therefore, the aggregated BESSs can participate in regulating the frequency of both low and high-frequency reserve services. Therefore, the objectives of this paper are: (1) Review the frequency control in the Great Britain power system; (2) Identify the inertia, the source of inertia, and the future challenge of an inertia reduction due to RESs; (3) Classify the new control methods for controlling the frequency such as demand response and DERs; (4) Use some model representation of a population of controllable loads; (5) Demonstrate the effectiveness of the controllable loads in controlling the frequency of a power system.

\section{Frequency control in power systems}

Frequency in a power system is a real-time changing variable that indicates the balance between generation and demand. In Great Britain, the National Grid is the system operator that is responsible for maintaining the frequency response of the power system within acceptable limits. Two main levels define these limits: the operational limit, which is equal to $\pm 0.2 \mathrm{~Hz}$ (i.e. $49.8 \mathrm{~Hz}$ to $50.2 \mathrm{~Hz}$ ), and the statutory limit, which is equal to $\pm 0.5 \mathrm{~Hz}$ (i.e. $49.5 \mathrm{~Hz}$ and $50.5 \mathrm{~Hz}$ ). Under a significant drop in the frequency (i.e. below $49.2 \mathrm{~Hz}$ ), a disconnection by low-frequency relays is provided for frequency control of both the generators and demand. Table 1 describes the frequency containment policy in the Great Britain power system [15-19].

Many of the interventions of the Great Britain system operator should be adopted for balancing the frequency. This can be carried out by integrating different balancing services, such as reserve services, system security services and frequency response services. These services aim to maintain the frequency within the acceptable limits and restore the frequency after sudden changes in the demand or generation. The services involve both generation and demand. The frequency response services include firm frequency response (FFR), mandatory frequency response (MFR) and enhanced frequency response (EFR), as indicated below [16].

\subsection{Firm frequency response}

This provides a dynamic or non-dynamic response to the changes in the frequency. This service is acquired from generators, except for in generators that provide MFR. In addition, it is provided from the demand through a competitive process of tenders. These tenders can be assigned for a low or high-frequency event or both [16].

\subsection{Mandatory frequency response}

This refers to an automatic change in the output of the active power of a generator in response to a pre-set value of frequency deviation. The grid code in the Great Britain power system requires the availability of this service in all large-capacity generators connected to the transmission system. Large generators can be defined as all generators with a capacity equal to or larger than 100 MW in England and Wales and equal to or larger than $10 \mathrm{MW}$ in Scotland. These generators work at under an $80 \%$ load and must provide a Primary response, a Secondary response and a high-frequency response, as stated below [16, 18]:

1) The primary frequency response is an automatic $10 \%$ increase in the output of a generator in response to a frequency drop within ten seconds and can be sustained for a further twenty seconds.

2) The secondary frequency response is an automatic $10 \%$ increase in the output of a generator in response 
Table 1 Frequency containment policy of Great Britain power system

\begin{tabular}{ll}
$\begin{array}{l}\text { Frequency limits } \\
(\mathrm{Hz})\end{array}$ & Case description \\
\hline \pm 0.2 & $\begin{array}{l}\text { System frequency under normal operating conditions and the maximum frequency deviation for a loss of generation or a } \\
\text { connection of demand up to } \pm 300 \mathrm{MW} \\
\text { Maximum frequency deviation for a loss of generation more than } 300 \mathrm{MW} \text { and less than or equal to } 1320 \mathrm{MW}\end{array}$ \\
\pm 0.5 & $\begin{array}{l}\text { Maximum frequency deviation for a loss of generation more than } 1320 \mathrm{MW} \text { and less than or equal to } 1800 \mathrm{MW} . \text { The } \\
\text { frequency must be restored to at least } 49.5 \mathrm{~Hz} \text { within } 1 \text { minute }\end{array}$ \\
\hline
\end{tabular}

to a frequency drop within thirty seconds and can be sustained for up to thirty minutes.

3) The high-frequency response is an automatic reduction in the output of a generator in response to a frequency rise within ten seconds and can be sustained indefinitely.

\subsection{Enhanced frequency response}

The provision of $100 \%$ of the output of the active power within one second following a pre-set value of a measured frequency deviation and can be sustained for up to fifteen minutes [18]. Recently, the National Grid contracted a total of $201 \mathrm{MW}$ of EFR services from energy storage systems through different providers. Most of these providers are expected to provide their services by the end of 2017 . Figure 1 shows the timescale for MFR and EFR services in the Great Britain power system [18].

\section{Inertia in power systems}

System inertia can be defined by the availability of the energy in the rotating mass of generators that are directly coupled to the power system [20]. System inertia determines the response of a power system to a frequency disturbance, such as a sudden loss of generation or load.

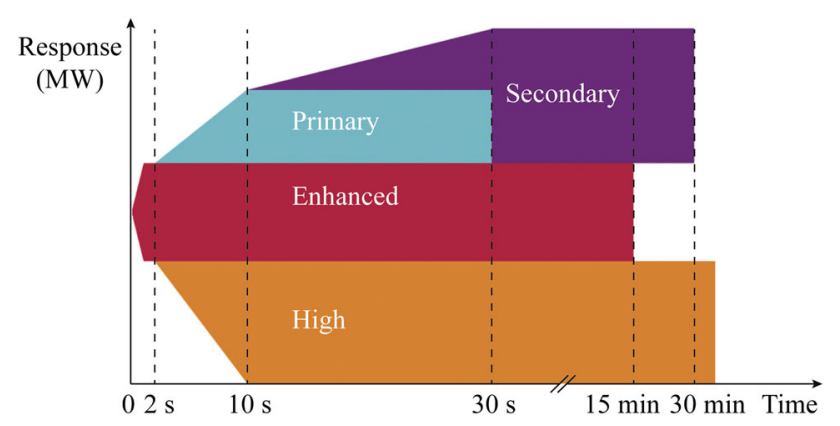

Fig. 1 Timescale of MFR and EFR in Great Britain power system

\subsection{Source of inertia in power system}

Large-capacity synchronous generators, i.e. in the Great Britain power system provide about $70 \%$ of the system inertia. The rest is provided by smaller synchronous generators and synchronous demand [18]. The National Grid is currently instructing conventional generators to run continuously, even if there are no economic profits since they are part-loaded. This creates a minimum level of available inertia to secure a capacity for frequency response [18]. This capacity is expected to be $30 \%-40 \%$ more than the current capacity in the next five years [21]. However, these generators are expensive to operate and produce large amounts of greenhouse gas emissions.

For example, the required capacity for FFR service in the summer is higher than other seasons due to low demand. Hence, fewer synchronous generators are committed to supplying that demand. This capacity varies from 400 to $700 \mathrm{MW}$ for the primary response, 1200 to 1450 MW for the secondary response and 0 to 150 for the highfrequency response [22]. As a result, the payments for frequency response services vary as well. Table 2 shows an example of the payments for July 2016 (summer) and January 2017 (winter) [23].

\subsection{Challenges of inertia reduction}

The absence of direct coupling between the machine and the power system in some RESs, e.g. wind and solar due to their power electronics, prevent their rotating mass from contributing to system inertia [20]. Therefore, RESs reduce the total system inertia, and hence, prompt decreased power system stability and increment the difficulties of the operation and control of the power system. RESs have power fluctuations due to the change of the wind speed and solar power, causing a significant impact on the stability of the frequency deviation.

Figure 2 shows the frequency drop and the required frequency response capacity of a simulated Great Britain power system employed by the National Grid. The simulations were performed for the system with $20 \mathrm{GW}$ of demand during a generation loss of $600 \mathrm{MW}$ and different values of the system 
Table 2 Payments for different frequency response services by National Grid in July 2016 and January 2017

\begin{tabular}{|c|c|c|}
\hline \multirow[t]{2}{*}{ Service type } & \multicolumn{2}{|c|}{ Payment cost (million $£)$} \\
\hline & July 2016 & January 2017 \\
\hline MFR & 2.40 & 2.33 \\
\hline $\begin{array}{l}\text { FFR plus frequency control } \\
\text { by demand management }\end{array}$ & 8.86 & 7.71 \\
\hline
\end{tabular}
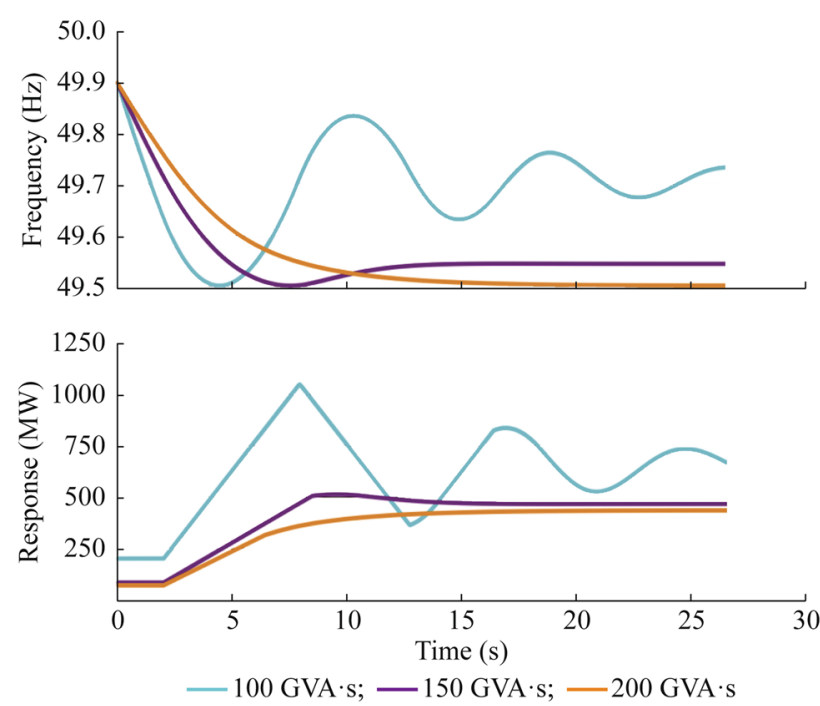

Fig. 2 Frequency simulation of 600 MW generation loss in Great Britain power system showing impact of inertia reduction

inertia [20]. When the system inertia decreases, the frequency response services procured are increased to maintain an acceptable level of security, as shown in Fig. 2 [20]. Table 3 shows some examples of the requirements of the frequency response for different values of inertia and generation loss. In addition, the inertia reduction across the entire power system will not have the same reduction levels; areas with high RESs have a higher frequency deviation than other areas shown in Fig. 3 [24, 25].

A reduction in the system inertia will increase the rate of change of frequency (RoCoF) when the system is subjected

Table 3 Frequency response requirements for different values of inertia and generation loss

\begin{tabular}{llc}
\hline System inertia (GVA·s) & \multicolumn{2}{l}{ Response requirement $(\mathrm{MW})$} \\
\cline { 2 - 3 } & 500 MW loss & $600 \mathrm{MW}$ loss \\
\hline 100 & 590 & 1285 \\
150 & 365 & 575 \\
200 & 365 & 365 \\
\hline
\end{tabular}

to sudden disturbances such as loss or increase in the demand or generation. In this situations, it is highly recommended to minimise the settling time during the disturbance period [10, 25-27]. Therefore, the need for additional frequency control is increased [20, 28]. A fast frequency response from the generation side is one of the recommended solutions to mitigate the increased frequency deviation issue [26, 29]. Also, the RESs alongside with the classical generators have potential to provide frequency control as ancillary service [30, 31].

The control system, which is responsible for controlling the frequency, must provide a fast and stable response [9, 32]. A rapid response to a high RoCoF is strongly recommended; however, a very quick response has a risk of system oscillations [9]. A flexible embedded real-time controller that offers higher flexibility versus low cost is required with the ability of event detection and response algorithm to any disturbance. The designed controller is preferable to have scalable parameters and fast controller latency to create a new adaptive protection system that is capable of standing against frequency collapse in future energy networks [26]. This scheme is intended to supplement local control, rather than replace it. Existing load shedding and governor-frequency control processes continue to be in place, but new forms of frequency control will decrease the degree to which the conventional response would be approached. This stage will allow the control scheme to be fine-tuned based on real measurements $[25,26]$.

\section{Demand side frequency response}

With the expanding needs of renewable energy resources, performing primary frequency control utilising just the generation side becomes noticeably expensive but also

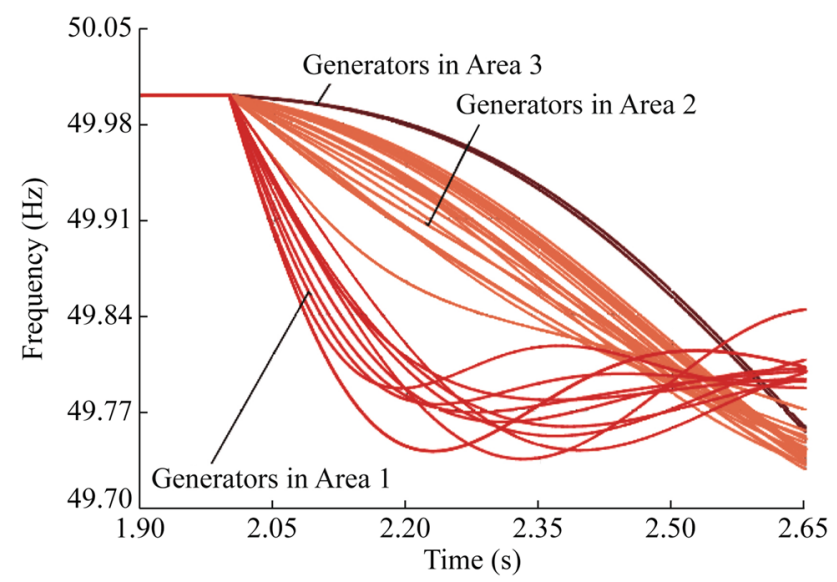

Fig. 3 Dynamic variation of frequencies measured showing different deviation values at different generator terminals in Great Britain power system 
technically difficult. In addition, the combination of high wind and solar output alongside with a low demand means that a significant number of interventions by the Great Britain system operator should be taken for balancing and operability reasons. Therefore, there are opportunities to further develop demand-side services during both periods of low and high demand [18].

Demand side frequency response presents a novel way to mitigate the increasing need in the conventional power generators [33-35]. The uses of the emergency power amount from the load side for the frequency reserve services presents a new challenge. The challenge is associated with the control of large distributed loads [4]. Especially, with the EVs, residential BESSs, water heaters, and cloth dryers.

\subsection{Demand-side integration}

Demand-side integration (DSI) measures how to use the loads and local generations to support system management and to improve power supply. The term 'demand-side integration' refers to the relationship between the power systems, energy supply and end users. This relationship includes demand-side management (DSM) and demandside response (DSR) [27]. The potential of DSI relies upon customer's, such as the duration and the timing of their demand response, the availability and the timing of the information provided to them, the automation of end-use equipment, metering, pricing/contracts, and the performance of the communications infrastructure [36].

There are two types of programs for the application of DSI: price-based programs and incentive-based programs $[37,38]$. In price-based programs, consumers adjust their energy consumption about the changes in electricity market price. In contrast, the latter is provided through curtailment or interruptible contracts where consumers are paid to shift or reduce their energy consumption [37].

In the Great Britain power system, a project on demandside integration estimated that the programs of demandside integration are more commercially viable for distribution network operators at medium voltage level than lower levels in term of investments [39].

However, it is important to address the challenges associated with the demand side integration, such as changing the natural diversity of loads, which can create more unpredictable and undesirable effects. For example, the amount of recovered energy through the DSR may be larger than the required load reduction [40].

\subsection{Control methods of demand for frequency response}

A flexible demand in industrial and public buildings, such as water supply companies, steelworks, the wastewater treatment industry, hospitals, factories, food markets and universities, can be controlled to provide frequency response in the Great Britain power system [41-43]. The estimated availability of this flexible demand from commercial and educational buildings is growing, and it was $2.5 \mathrm{GW}$ in 2012 in the Great Britain power system, as shown in Table 4 [44].

Two control methods were used in the literature to control flexible demand units: centralised and decentralised control methods. The loads with a thermal storage showed suitable characteristics to provide a provision of demandside frequency response than other types of loads [41, 45-47].

Centralised control of the demand units relies on the infrastructure of information and communication technology (ICT) to provide communications between the unit and the centralised control of the aggregator [48]. For instance, a centralised frequency controller presented in [49] sends a signal to turn ON/OFF domestic air conditioning units and water heaters after a pre-set value of frequency rise/dip. The centralised controller reduces the uncertainty in the response of controllable units. However, the establishment of communications in the centralised method presents challenges, such as cost and latency.

To overcome these challenges, decentralised frequency controllers were developed. A decentralised controller, presented in [46], regulated the set-points of the temperature of refrigerators according to the variation in frequency deviation and its power consumption was controlled. A dynamic decentralised controller was developed in [45] to change the aggregated power consumption of refrigerators in a linear relationship with a frequency change. The controller planned to abstain from influencing the primary cold supply function of refrigerators. Similar controllers were developed to provide a frequency response from industrial bitumen tanks [41] and melting pots [50].

Table 4 Estimated flexible demand in Great Britain power system during a peak hour of a winter day

\begin{tabular}{ll}
\hline Sector type & Capacity $(\mathrm{GW})$ \\
\hline Retail & 0.7 \\
Education & 0.3 \\
Commercial & 0.3 \\
Other non-domestic sectors & 1.2 \\
Total capacity & 2.5 \\
\hline
\end{tabular}


The required availability of refrigerators to provide frequency response was estimated by work presented in [51]. It was estimated that approximately 1.5 million refrigerators are required to provide $20 \mathrm{MW}$ of response. The total cost of frequency controllers added to each refrigerator was calculated in 2007 at a price of approximately $£ 3$ million ( $£ 2$ million of an estimated cost for each controller) [46].

\subsection{Thermostatically based controllable loads}

Recently, the thermostatically based controllable loads (TCLs) such as refrigerators, air-conditioners, and ceiling heaters have been widely considered in the literature due to the potential short-term modulation of their aggregate power consumption [24, 52-61]. TCLs have an electrical heating/cooling thermostat controlled-based device. It modulates the used power for cooling/heating to maintain the temperature nearly to the desired level shown in Fig. 4. The most common implementation of these loads is that the thermostat takes the advantages of the temperature deadband around the desired level [55].

In Great Britain's power system, the DSR was evaluated and considered in applications of the frequency control $[56,57,62]$. The aggregation of the TCLs for the DSFC in the Great Britain power system was investigated in $[56,57]$. The DSR model was used to regulate the dynamic of the TCLs. This model was used to obtain the optimal power consumption and allocated sufficient ancillary services. This model was developed for a multi-stage stochastic unit commitment and integrated into a mixed integer linear programming formulation. It was proposed to deal with the future inertia reduction under future lowcarbon scenarios. The study cases were focused on the total system cost and the produced amount of the $\mathrm{CO}_{2}$ emission [57].

In addition, domestic refrigerators as an example of the TCLs DSFC in the Great Britain power system was proposed in [56] to deal with the future inertia reduction. The

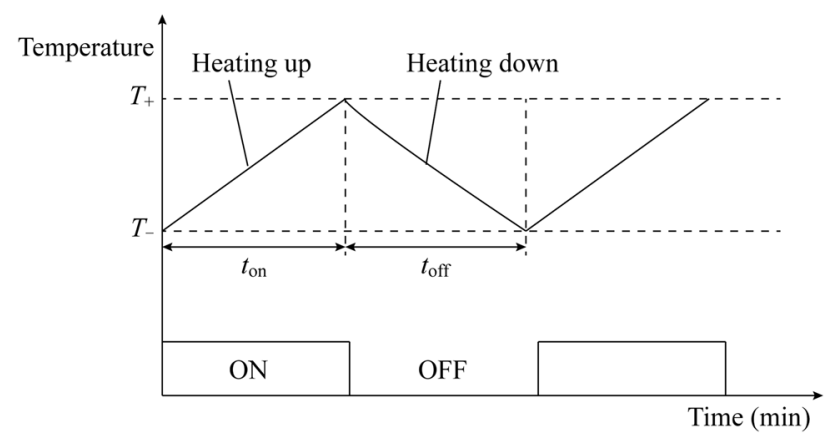

Fig. 4 A typical temperature control of a thermostat-based heating device method presented a non-real-time communication-controlled TCLs. The aggregated power of the TCLs was controlled as a linear function of the local frequency change. A novel technique was developed in [56] for estimating the infeed loss and post-fault in a power system.

Markov chain model was applied to represent the aggregated power consumption of the TCLs population for DSR [33-35, 63]. A hierarchal DSR framework with two layers was presented in [63]. The top layer is used to obtain the control gain of the drooping amount. This value was sent to the local layer, which involves a population model including different devices. The local layer changed their power consumption of the controllable loads to meet the value of the control gain. The local layer had a Markov chain-based frequency controller to change the power consumption to meet the gain value probabilistically. The TCLs were designed according to three operation states, ON, OFF, and LOCK [63]. Similarly, the same framework for DSR was used in $[33,35]$ to represent the TCLs but with four operation states, ON, OFF-LOCKED, OFF, and ON-LOCKED.

\subsection{Water heaters}

Electric water heaters are ideal home appliances, which can be controlled to provide frequency response services by turning $\mathrm{ON} / \mathrm{OFF}$ the device in response to a pre-set value of frequency deviation [64-68]. There are two main types of water heaters: the electric resistance water heater (ERWH) and the heat pump water heater (HPWH). In addition, a hybrid type of water heater has both types incorporated in the same unit [69].

Both types of electric water heater have the same potential of providing different frequency services. The only difference is that HPWH has a compressor so that the response of the device will be different from ERWH regarding the number of responses. For example, when the compressor becomes OFF during the service, it requires several minutes to be $\mathrm{ON}$ again limiting the availability of these devices [67, 68, 70]. In contrast, the ERWH has no compressor so that the device can be switched ON/OFF at any time during the service if the water temperature is still below the user-defined level [64, 71, 72]. In general, water heaters have many advantages [64-68]. For example:

1) There is a large population of water heaters in the present and future power system. The water heater has a power consumption higher than other home appliances, such as dryers, washing machines and refrigerators. For example, in certain areas in the USA, water heaters consume about $30 \%$ of the household load, which contributes significantly to the peak load. 
2) Water heaters can be used as energy storage devices by heating up water to a higher temperature than its normal range. Hence, no energy is wasted in providing balancing services, and there is no impact on customers' comfort.

The modelling and control of water heater devices are widely covered in the literature to support the frequency in power systems [64, 71, 72]. Markov chain was used to represent the aggregated power for a various controllable population of water heaters for DSFC [33-35, 63]. A hierarchal control framework for the demand side frequency control with two decision layers was presented in [73-75]. The top layer is the supervisory control of the aggregator, while the local layer is for the devices population and a frequency controller. The dynamic behaviour of the controllable load was represented by using Markovbased states [73-76]. The electric resistive water heater was represented by two states (ON and OFF) while the heat pump water heater was represented by four states ON, OFF-LOCKED, OFF, and ON-LOCKED [76]. Markov chain-based states are representing the dynamic behaviour of the switching in the end-user controllable water heater devices. Hence, it represents the population of those controllable devices. The controller changed the power consumption of controllable loads with an amount according to the gain value sent by the supervisory control Layer. The gain value was calculated according to the number of the system loads and the controllable loads (see further details in [73-75]).

\subsection{Electric vehicles}

Recently, an increasingly ambitious target for a high level of EV integration was announced around the world. An internationally high priority target was placed on deploying and developing the technology for EVs [31, 77]. It is assumed that the annual production of EVs would be over 100 million by 2050 [77].

The UK government has declared that EVs are anticipated to play a major role in future transport sectors. The increased interest in EVs leads to a significant impact on power systems [31].

However, the high uptake of EVs introduces a new challenge to the planning and operation of current and future power systems. This challenge relates to the uncontrolled charging of EVs, or so-called 'dump charging'. This uncontrolled charging may create a new peak load, such as charging when EV owners return home from their last day trip [77].

EVs' load can be controlled to provide frequency response service in a power system. However, providing a primary frequency response from EVs in certain cases can introduce a negative impact on power system stability. This impact is due to insufficient load estimation of aggregated EVs [78]. The common approach to provide a demand-side frequency response from EVs is to control the charging/ discharging rates of vehicle-to-grid (V2G). There are many types of control and management of loads (including EVs), such as reducing users' bills, charging coordination of EVs and charging scheduling [79].

Load control with the integration of EVs and distributed generators was presented in [5] for the power regulation. The load-shifting optimisation problem was solved according to technical and market conditions. This approach is applicable for various DERs, such as the EVs' smart charging [5].

\subsection{Battery energy storage systems}

Energy storage systems are among key factors for future smart grids $[9,29,80]$. BESSs are evaluated and considered in the literature for the frequency regulation $[13,14,29]$. Also, the estimated growth of storages in the Great Britain power system by 2050 will be about $10.7 \mathrm{GW}$ based on the 'consumer power scenario' [81]. Also, residential and non-residential BESSs are growing up day by day due to the technical developments and cost reduction as well as high levels of photovoltaic (PV) integration $[14,81]$. A large number of these batteries are connected to distribution networks installed behind the meter [81]. The BESSs present a fast dynamic response to compensate the load variations in distribution networks. In the Great Britain power system, many tenders were taken into consideration by the National Grid to provide an enhanced frequency response from BESSs [81, 82].

The application of BESSs in direct load control (DLC) is proposed in [83]. The combination of electrical load, the load level in the building, and their controllable devices were considered to investigate the DLC application. The problem of controlling many distributed small-scale BESSs was highlighted as well. The scheme presented in [83] is reducing the frequency deviation by controlling the state of charge (SOC) of the batteries installed behind the meters [83]. A coordination method of batteries charging was presented in [13] for controlling neighbouring batteries to regulate the frequency and voltage.

Markov-chain was previously depicted to represent dynamic behaviour of the battery SOC for EV batteries [84] or PV charging-based batteries [85]. The modelling of the batteries SOC for the power supply availability from PV was presented in [85]. The model was used to improve the availability of PV generation and to understand the nature of the charge/discharge rates of the batteries supplied by PV. The dynamic representation of BESS's SOC was designed according to many states transitions, from 
zero to full charge and vice versa [85]. Various types of batteries and their applications were presented such as behind meter BESSs (home-based) [83], smart charging of EVs [86], and large-scale BESSs (grid-scale BESS) [87]. The aggregation of these types is important in regulating the power system frequency $[83,86,87]$.

\section{Control of DERs}

DERs include energy storage systems, demand response and distributed generation (DG). Different approaches are presented in the literature to control and coordinate the operation of DERs. Many of these approaches aimed to actively integrate DERs into distribution networks rather than through a conventional passive connection to achieve a more secure and economical operation than with conventional methods.

Breaking the distribution network into smaller areas, such as microgrids, or wider control areas, such as cells, is one of the active approaches to manage DERs [36]. Both cells and nicrogrids are pointed at managing and coordinating the DERs to supply their local demand. Virtual power plant (VPP) is another control approach, which was established to manage DERs. VPP intended to aggregate different types of DERs to represent a special type of power unit to participate in the energy market [36].

\subsection{Microgrids}

A microgrid is a small area of a distribution network that involves different types of DERs and can operate in the island or grid-connected mode to supply local energy demand [88]. The control in a microgrid means to regulate both frequency and voltage. The coordination of DERs within a microgrid presents a novel way to increase the benefits to the overall system performance, such as reducing losses of feeders, compensating the fluctuation of RESs, improving power quality and supporting local frequency and voltage [36, 88].

Autonomous microgrids for an instant, has both renewable energy generation and energy storage system. Both of them have to be coordinated to regulate the frequency within the Microgrid by compensating the mismatch of load and generation. This control or functionality called or known as load frequency control (LFC) of a microgrid [89, 90].

Therefore, automated and robust balancing mechanism is required especially in the islanded situation. Microgrids have different inverter-based DERs, and therefore, controlling these inverter-based DERs is the key point in the stability of the frequency [91]. Centralised and decentralised control solutions were introduced to control a microgrid. The centralised method requires an expensive communication infrastructure [90-92].

The decentralised control structure reduces the cost of the communications. This method considered the gridconnected mode, or the nature of the inverter's primary source has not been considered. Distributed control of microgrids is growing up day by day as it compromises both positive features of centralized and decentralized controls [91]. During grid-connected mod, the control of a microgrid is simple, since the large grid dominates the microgrid dynamics [93].

\subsection{Wider control area (cells)}

The 'cells' concept was introduced to overcome the challenges when more than $50 \%$ of the total generation capacity is from DG. The high penetration of DG introduces a fluctuated impact on the power system, as this is the case in the Danish power system [36, 94].

Therefore, a cell is a wide area in a distribution system with a group of controlled DERs [36]. Like the microgrids, the control in this area covers both frequency and voltage and can work on the island or grid-connected modes. In the normal operation mode, cell effectively manages its DERs. In the case of a regional emergency, such as a real risk of a blackout, it disconnects itself from the grid and moves to the islanded mode $[36,94]$.

\subsection{Virtual power plant}

VPP aggregates different types of DERs to make them visible to the system operator as a single controlled unit to participate in the ancillary services [95, 96]. The output of the aggregated DERs in a VPP is arranged to be as a central generation unit with commercial and technical roles [95]. The commercial role of a VPP is driven by the activity of market participation, such as energy supplier. In contrast, the technical role of a VPP was driven by the activity of the system management and support [96].

\subsection{Wind turbine generators}

Wind turbine generators (WTGs) were widely installed and its capacity in power systems around the world is growing day by day due to the improvements in technology and cost reduction [97-100]. In the US, for example, WTGs represented a $33 \%$ of the total additional power generation since 2007. By the end of 2013, the total installed WTGs in the USA was over $61.1 \mathrm{GW}$ and about $12 \mathrm{GW}$ was under constructions [99].

However, higher penetration of WTGs in a power system introduces new challenges for the operation and control of power systems. These challenges are mainly due to 
the interact of different WTG capacities with the power system. Particularly, the stability of the frequency response decreases due to power electronics interface decouples the WTGs inertias from the system [97, 99, 101, 102].

It was found that the integration of wind turbine generation without frequency control leads to a negative impact on the frequency response. Therefore, frequency regulation mode shode carried out [99].

\subsection{Load shedding for stability support}

The last defence line to achieve a stable and safe operation of a power system is under frequency load shedding (UFLS) and under voltage load shedding (UVLS) $[103,104]$. These two techniques are also useful and necessary to avoid any collapse in frequency or voltage.

The developments in large power systems, such as integrating more RESs, as well as the complex network refurbishments, the safety of the system operation is facing more challenges. Therefore, current traditional UFLS/ UVLS methods can lead to inadequate load shedding, thus leading to more economic losses [103]. As a result, the traditional methods for load shedding are unable to meet the growing needs of modern power systems. In this situation, smart devices such as such as wide-area measurement systems and synchrophasor concept can be used effectively to support the frequency and voltage [103, 104].

The wide-area monitoring system (WAMS) is rapidly increasing due to its importance in modern power systems operators. Wide-area monitoring, protection and control (WAMPAC) has already been used by many systems operator especially with UFLS [104].

\section{Summary of challenges and new control methods}

The frequency control limits in the Great Britain power system are defined by the system operator using two main levels: the operational limit, (i.e. equal to $\pm 0.2 \mathrm{~Hz}$ ), and the statutory limit, (i.e. equal to $\pm 0.5 \mathrm{~Hz}$ ). The frequency response services in the Great Britain power system are used by the system operator to maintain frequency within the acceptable limits and to restore frequency following sudden changes in demand/generation [24, 74].

Large-capacity synchronous generators provide the majority of inertia in the Great Britain power system. The rest is provided by smaller synchronous generators and demand. Conventional generators in the Great Britain power system are continuously run to create a minimum level of inertia to secure a and adequate capacity for the stability of frequency response. This capacity is expected to be increased more than current capacity in the next five years. However, these generators are expensive to operate and produce large amounts of greenhouse gas emissions.

The absence of direct coupling between the rotating machine and the power system in some RESs, e.g. wind and solar due to the power electronics leads to a reduced inertia. Therefore, increase the difficulties of the power system operation and control. In addition, RESs have power fluctuations due to unpredictable environmental conditions causing a significant impact on the stability of the frequency. A reduction in the system inertia will increase the RoCoF when the system is subjected to abrupt disturbances such as loss or increase in the demand or generation. In this situation, it is recommended to minimise the settling time of the response during the disturbance period. As a result, the need for additional frequency control is increased due to an increased level of RESs. A fast frequency response from the generation side is one of the recommended solutions to overcome the issue of the increased frequency deviation.

The new control system of the frequency, must provide a fast and stable response to a high RoCoF. This is highly recommended; however, a fast response has a risk of system oscillations. A flexible embedded real-time controller is required with the ability of event detection and response algorithm to any disturbances. This controller offers higher flexibility versus low cost and is preferable to have scalable parameters and fast controller latency. This is to create a new adaptive protection system which is capable of standing against frequency collapse in modern power systems. This control scheme is intended to supplement local frequency control, rather than replace it.

There are opportunities to further develop demand-side services during both periods of low and high demand due to the increasing needs of RESs. However, using the power from the load side for the frequency reserve services presents a new challenge. The challenge is about the control of these many distributed loads, especially, with the EVs, residential BESSs, water heaters, and cloth dryers.

The estimated level of storage in the Great Britain power system by 2050 will be about $10.7 \mathrm{GW}$ based on 'consumer power scenario of UK system operator'. Also, residential and non-residential BESSs are growing daily due to the developments in cost reduction as well as high levels of PV integration. A large number of these batteries are in distribution connected to the meter. The BESSs present a fast dynamic response to compensate the load variations in distribution networks. In the Great Britain power system, National Grid, which is the system operator, considered many tenders to provide enhanced frequency response from BESSs [24]. 


\section{Evaluation and simulation results}

The evaluation of the DERs integration for the frequency control was carried out in the MATLAB PowerSim. The simulation results were saved as vectors to visualise the comparison.

\subsection{Modelling of some controllable loads}

DERs have been rapidly increased due to their effectiveness in the cost and response speed [2,3]. DERs cover different types of power sources such as RESs, DSFC, BESS and EVs. This paper reviews and evaluates the integrating of the DSFC and the BESS-based DER applications for the power system frequency control. The DSFC consider the aggregation of the water heater devices such as the electric resistance water heater (ERWH) and the heat pump water heater (HPWH). The BESS-based DERs represent the aggregation of different types of DERs such as the smart EVs charging, large-scale BESSs, home-based BESS.

\section{1) Water heaters}

DSFC presents a novel way to mitigate the difficulties of the increased need for the active power generation. The TCLs such as refrigerators, air-conditioners, and water heaters have been widely considered due to the short-term modulation of their aggregated power consumption $[10,12]$. TCLs modulate the used power for cooling/ heating to maintain the temperature nearly to the desired level. In Great Britain power system, the DSFC was considered in the applications of the modern power system's frequency control $[10,12]$. A novel technique was proposed in [56] for the domestic refrigerators, as an example of the TCLs demand side frequency control in the Great Britain power system. It was proposed to deal with the future inertia reduction and for estimating the infeed loss and post-fault restoration. Also, the method presented a non-real-time communication-controlled TCLs. Aggregated power of the TCLs was controlled as a linear function of the local frequency change [56].

The water heater aggregation has also been presented as an example of TCLs for the DSFC. The representation of the ERWH and HPWH were modelled in $[10,76]$ based on Markov chain states diagram in Fig. 1. The device model was designed using Markov chain matrices to represent the power consumption of the aggregated power amount. The HPWH was modelled using four operation states: ON, OFF-LOCKED, OFF, and ON-LOCKED. The assumption of these states that the devices when switched to ONLOCKED or OFF-LOCKED it will remain in this state during the control period in Fig. 2. The ERWH was modelled using two states ON and OF only. The $\mu_{0}$ and $\mu_{1}$ are the switching probability factor from one state to another shown in Fig. 5.

The hierarchal DSFC in $[10,76]$ has two main layers. The local device (Layer 1) measures the non-zero frequency deviation and probabilistically change their power consumption by switching ON/OFF their controllable amount of power. The amount of the switching probabilities is set according to the value of $\mu_{0}$ and $\mu_{1}$. Layer 2 obtains this value according to the value of the $\Delta F$ measured in the Layer 1, more details are found in [10, 76]. This representation will be used in this paper to investigate the integration of these devices as a type of the DERs.

\section{2) BESS-based DERs}

BESSs are seen as key technologies for the future smart grids $[9,80,84,105-108]$. BESSs are evaluated and considered in the literature for the frequency regulation $[13,14]$. The BESSs presented a fast dynamic response to compensate the load variations on the grid side and hence regulate the frequency. The application of the BESSs DLC is proposed in [83] highlighted the problem of integrating small-scale BESSs. The scheme was effective in reducing the frequency deviation by controlling the behind-meters BESS SOC [83]. Also, a coordinated BESS was presented in [13] to control the neighbouring BESS and to regulate the frequency and voltage.

The BESS SOC model is considered in the literature by recognizing distinctive design techniques for the application of the frequency regulation $[14,85,109,110]$. Markov chain was previously used to represent the dynamic behaviour of the BESS mechanism in either EV-based BESS [84] or as a PV charging-based BESS [85]. The modelling of the BESS SOC for the power supply availability was presented in [85] and was used to improve the availability of the photovoltaic generation to understand the nature of the charge/discharge rates. The dynamic representation of the BESS's SOC has been designed according to many states transitions, from zero to full charges and vice versa

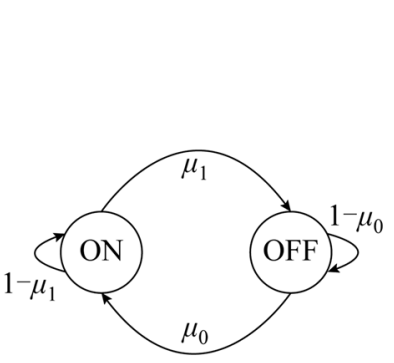

(a) ERWH

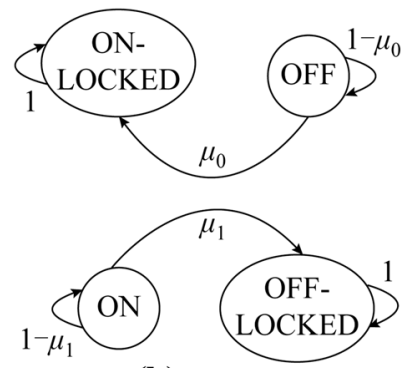

(b) HPWH
Fig. 5 Markov-based state transition diagram of dynamic load behaviour 


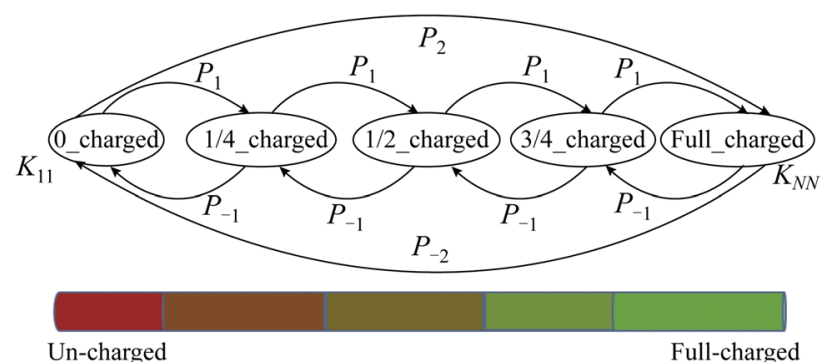

Fig. 6 State transition diagram representing dynamic behaviour of SOC's population

[85]. The Markov chain-based BESS's SOC representation proposed in [85] shown in Fig. 6 was used to model the dynamic behaviour of the BESS-based DERs' evaluation in this paper. It is representing the aggregation of different types of DERs such as the smart EVs charging, large-scale BESSs, home-based BESS [11].

\subsection{Evaluation assumptions}

The evaluation of the DERs integration is based on previous models' representation proposed in the literature. The assumptions considered for this evaluation are as follow:

1) The BESS inverters are smart, and a high controllability of the SOC is available.

2) The SOC level of the population is different during the same day and the year. Therefore, there are three different initial conditions for the aggregated population, representing three levels of SOC: high, medium, and low SOC shown in Table 5.

3) There are three aggregators with three different BESS aggregation types, which are aggregation of residential-based BESS, aggregation of a large-scale BESS, and aggregation of the EVs' in either home-based or station-based smart charging, shown in Table 6.

4) There are three aggregators considering three different DSFC aggregation types, which are ERWH and HPWH, shown in Table 7.

Table 5 BESS SOC initial conditions study cases

\begin{tabular}{llllll}
\hline Initial conditions & \multicolumn{5}{l}{ SOC population level (\%) } \\
\cline { 2 - 6 } & 0 & 25 & 50 & 75 & 100 \\
\hline High & 0.1 & 0.1 & 0.1 & 0.3 & 0.4 \\
Medium & 0.4 & 0.2 & 0.2 & 0.1 & 0.1 \\
Low & 0.6 & 0.2 & 0.2 & 0 & 0 \\
\hline
\end{tabular}

Table 6 Power assumption of each aggregator and their controllable BESS-based DERs

\begin{tabular}{llllc}
\hline \multirow{2}{*}{ Aggregator } & \multicolumn{4}{c}{ Population of aggregated controllable amount $(\mathrm{MW})$} \\
\cline { 2 - 5 } & Large-scale BESS & PV home-BESS & EVs & Total \\
\hline 1 & 30 & 20 & 30 & 80 \\
2 & 40 & 22 & 30 & 92 \\
3 & 40 & 30 & 40 & 110 \\
\hline
\end{tabular}

Table 7 Power assumption of each aggregator and their controllable DSFC

\begin{tabular}{lllc}
\hline \multirow{2}{*}{ Aggregator } & \multicolumn{2}{c}{ Population of aggregated controllable amount } & $(\mathrm{MW})$ \\
\cline { 2 - 4 } & ERWH aggregation & HPWH aggregation & Total \\
\hline 1 & 30 & 50 & 80 \\
2 & 42 & 50 & 92 \\
3 & 50 & 60 & 110 \\
\hline
\end{tabular}

Table 8 Study cases for simulation results with South East Australian power system

\begin{tabular}{lrrr}
\hline Aggregator at & \multicolumn{3}{l}{ Study cases } \\
\cline { 2 - 4 } & A1 & A2 & A3 \\
\hline 1-Bus 206 (Area 2) & 80 & 80 & 80 \\
2-Bus 312 (Area 3) & 0 & 0 & 110 \\
3-Bus 408 (Area 4) & 0 & 92 & 92 \\
Total (MW) & 80 & 172 & 282 \\
\hline
\end{tabular}

5) Three study cases are considered for the integration of the aggregators to represent DERs availability shown in Table 8.

6) The service is available for 24 hours and provides its full controllable amount of the power for the Great Britain primary frequency reserve period (10-30 s).

7) The initial values of all cases were $(30 \% \mathrm{ON}, 10 \%$ OFF-LOCKED, 50\% OFF, $10 \%$ ON-LOCKED), and (30\% ON, 70\% OFF) for HPWH and ERWH, respectively.

\subsection{Simplified Great Britain power system}

Simplified Great Britain power system model shown in Fig. $7[26,29]$ is used with the aggregation of various generation units. The generation amount and the inertia value were calculated according to the official reports from the National Grid (the Great Britain system operator) [111]. The disturbance of 2008 event sequence in the Great 


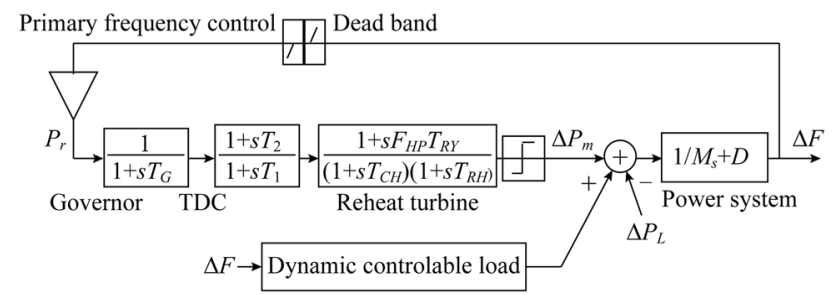

Fig. 7 Simplified Great Britain frequency control model

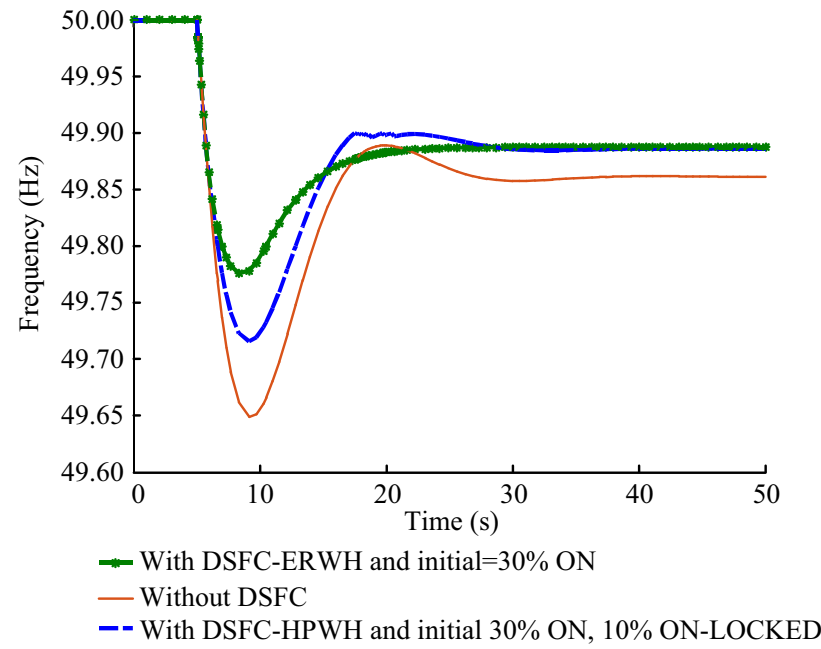

Fig. 8 Frequency response of simplified Great Britain power system and DSFC

Britain power system was considered and is equal to 0.03 p.u. [26, 29]. The SOC-high initial condition in Table 1 was used in this section. Figure 8 shows the frequency response with the integration of the DSFC while Fig. 9 shows the same response with the BESS. Both figures show the effectiveness of integrating such DERs in improving the frequency deviation and error.

\subsection{South-East Australian power system}

The Southern and Eastern Australian system shown in Fig. 10 was used for testing the new control techniques [112-114]. The disturbance occurred on $28^{\text {th }}$ September 2016 in the South Australian power system was considered (with load case 4 as in [34]). The disturbance sequences where losing of approximately $311 \mathrm{MW}$ wind power was applied at time $t=5 \mathrm{~s}$ in the simulation studies. This disturbance was considered as a sudden increase in the load at B404 near the generation unit GPS_4 in Area 4.

\section{Scenario 1: different capacity of DSFC}

In this scenario, considering by integrating the DSFC of Table 7 , the case studies for the aggregation of DER

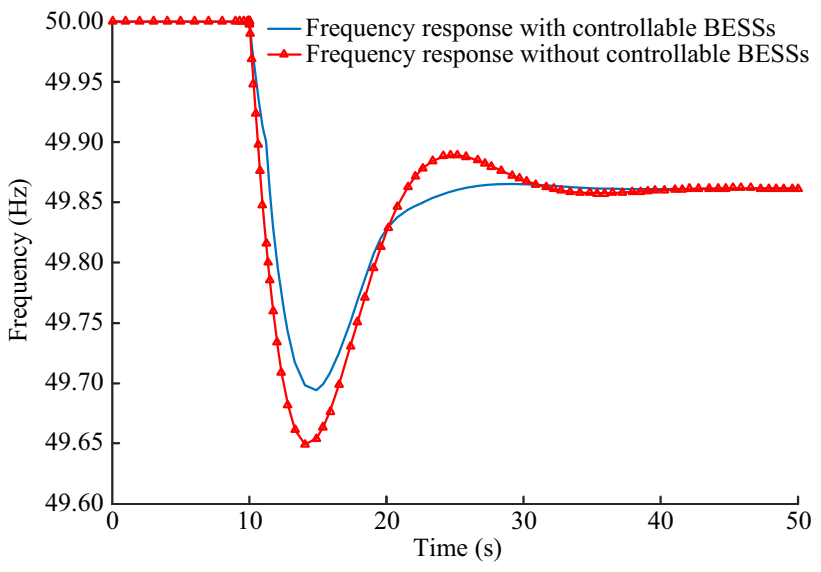

Fig. 9 Frequency response of simplified Great Britain power system and controllable BESS

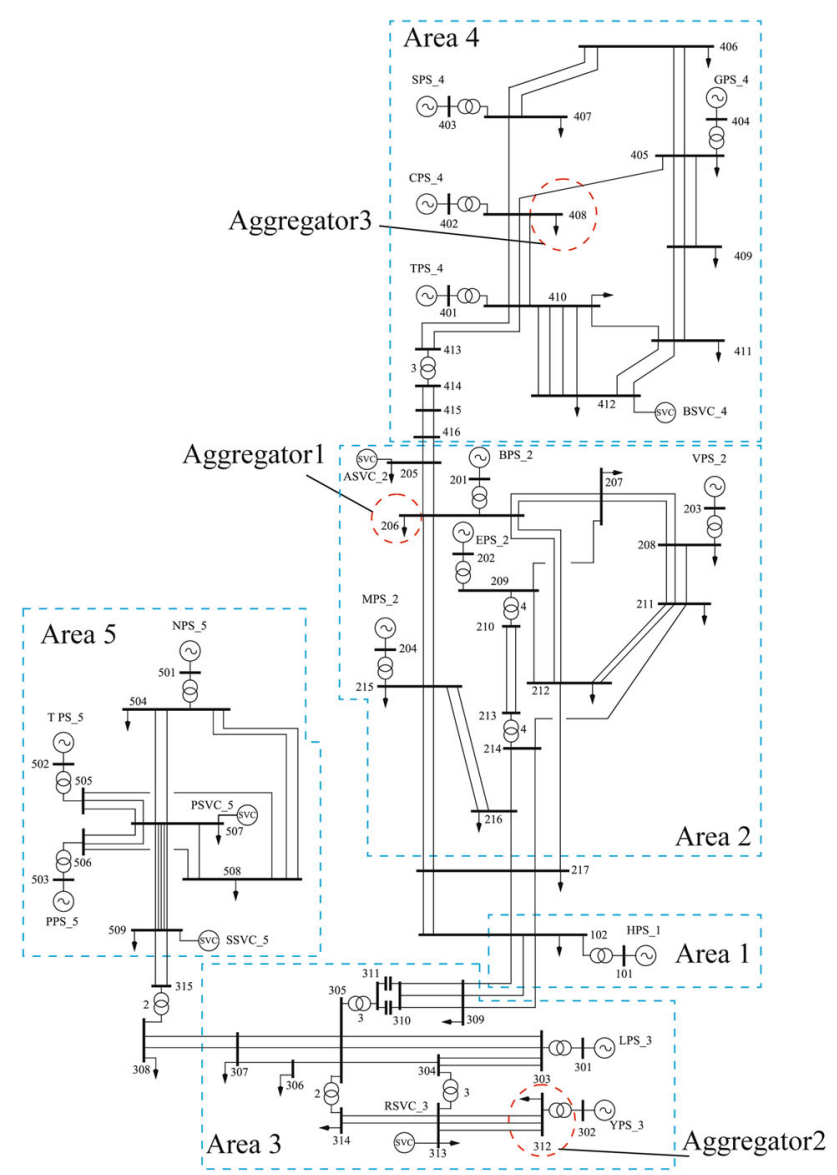

Fig. 10 South-East Australian power system

presented in Table 8 . Figure 11 shows the simulation results of the frequency response at different power units. Increasing the aggregators, and hence, increasing the 


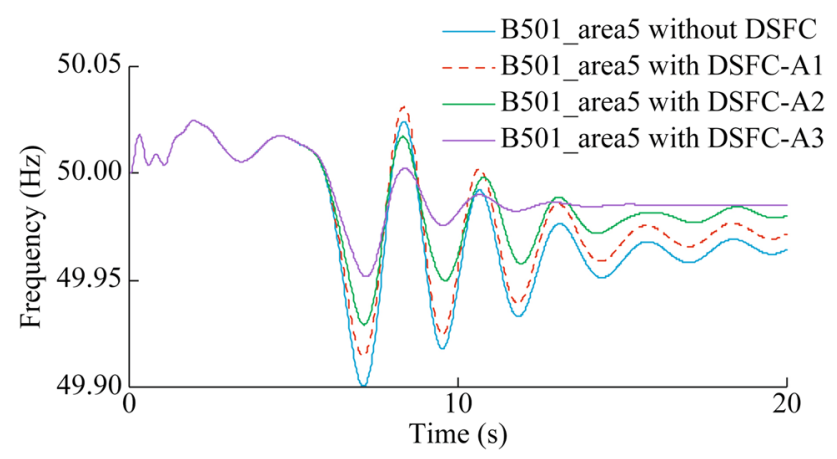

Fig. 11 Frequency response comparison of power generation units at B501-area 3 with DSFC Scenario 1

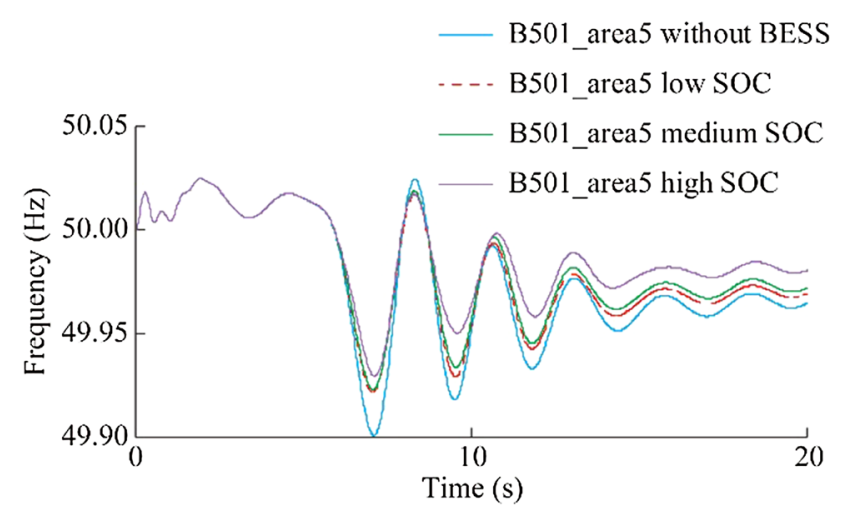

Fig. 12 Frequency response comparison of power generation units at B501-area 3 with BESS Scenario 2

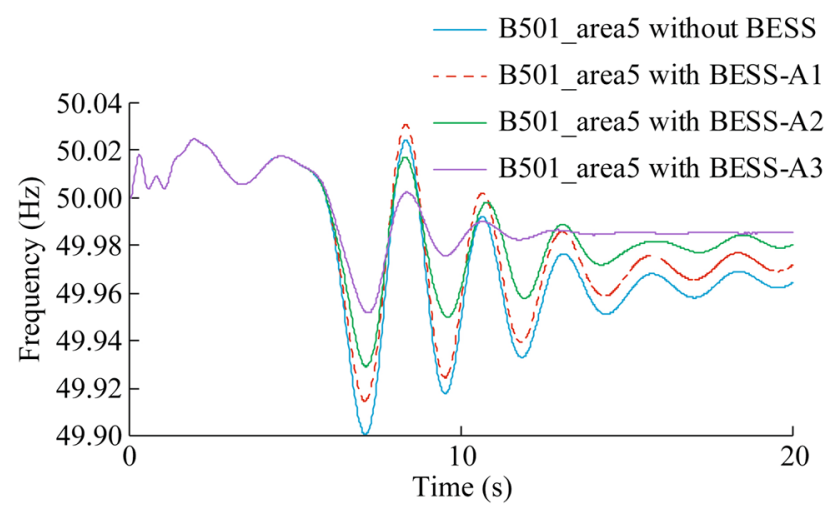

Fig. 13 Frequency response comparison of power generation units at B501-area 3 with BESS Scenario 3

amount of controllable DSFC leads to a reduction in the frequency deviation.

\section{Scenario 2: different BESS SOC initial conditions}

In this scenario, the BESS initial conditions shown in Table 5 with the A2 study case in Table 8 were considered. Figure 12 shows the simulation results by integrating BESSs with different SOC population initial conditions.
The results demonstrated the effectiveness of the BESSbased DERs in the dynamic response to a frequency change.

\section{Scenario 3: different capacity of BESSs}

In this scenario, the BESS high initial conditions shown in Table 5 with the study cases in Table 8 were considered. Figure 13 shows the simulation results by integrating BESSs with different aggregators study cases. The simulation results demonstrated that increasing the BESS integration leads to more improvement in the system frequency response.

\section{Conclusion}

The paper presented a review and evaluated of the integration of DERs for the applications of the frequency regulation in future power systems. The integration of the demand side frequency control and the BESS as types of DERs were considered. The aggregations of ERWHs and HPWHs were modelled based on models presented in the literature. The representation of a population of BESS and their applications such as aggregation of residential-based BESS, aggregation of a large-scale BESS, and aggregation of the EVs' in either home-based or station-based smart charging were used. The Great Britain power system and the 14-machine South-East Australian power system were employed to demonstrate the effectiveness of the new methods in controlling the frequency. Different study cases of DERs availability were modelled, and real disturbances were utilised. The frequency response was highly improved by integrating various DERs. Aggregation of $172 \mathrm{MW}$ and $282 \mathrm{MW}$ of water heaters and BESS-based DERs reduced the frequency deviation and error following a disturbance in the South-East Australian power system with $14.5 \mathrm{GW}$ system load base.

Open Access This article is distributed under the terms of the Creative Commons Attribution 4.0 International License (http:// creativecommons.org/licenses/by/4.0/), which permits unrestricted use, distribution, and reproduction in any medium, provided you give appropriate credit to the original author(s) and the source, provide a link to the Creative Commons license, and indicate if changes were made.

\section{References}

[1] Ghafouri A, Milimonfared J, Gharehpetian GB (2015) Coordinated control of distributed energy resources and conventional power plants for frequency control of power systems. IEEE Trans Smart Grid 6(1):104-114

[2] Rui Y, Yingchen Z (2016) Coordinated optimization of distributed energy resources and smart loads in distribution 
systems. In: Proceedings of 2016 IEEE power and energy society general meeting, Boston, USA, 17-21 July 2016, 5 pp

[3] Wu D, Yang T, Stoorvogel AA et al (2017) Distributed optimal coordination for distributed energy resources in power systems. IEEE Trans Autom Sci Eng 14(2):414-424

[4] Chapman AC, Verbic G (2016) Dynamic distributed energy resource allocation for load-side emergency reserve provision. In: Proceedings of IEEE innovative smart grid technologiesAsia, Melbourne, Australia, 28 November-1 December 2016, 6 pp

[5] Georgiev M, Stanev R, Krusteva A (2016) Flexible load control in electric power systems with distributed energy resources and electric vehicle charging. In: Proceedings of IEEE international power electronics and motion control conference, Varna, Bulgaria, 25-28 September 2016, 7 pp

[6] Huang S, Wu Q, Liu Z et al (2014) Review of congestion management methods for distribution networks with high penetration of distributed energy resources. In: Proceedings of IEEE PES innovative smart grid technologies, Istanbul, Turkey, 12-15 October 2014, $6 \mathrm{pp}$

[7] Yang J, Wang Y (2014) A review of the effects of distributed energy resources and power-electronic controlled loading on distribution network stability. In: Proceedings of IEEE conference on industrial electronics and applications, Hangzhou, China, 9-11 June 2014, 6 pp

[8] Apostolov AP (2011) Modeling of legacy intelligent electronic devices for UCA based substation integration systems. In: Proceedings of large engineering systems conference on power engineering, Halifax, Canada, 11-13 July 2001, 6 pp

[9] Cheng M, Sami SS, Wu J (2016) Benefits of using virtual energy storage system for power system frequency response. Appl Energy 194:376-385

[10] . Obaid ZA, Cipcigan LM, Muhssin MT (2017) Design of a hybrid fuzzy/Markov chain-based hierarchal demand-side frequency control. In: Proceedings of IEEE PES GM, Chicago, USA, 16-20 July 2017, 5 pp

[11] Obaid ZA, Cipcigan LM, Sami SS et al (2017) Control of a population of battery energy storage systems for dynamic frequency control institute of energy. Dissertation, Cardiff University

[12] Muhssin MT, Cipcigan LM, Jenkins N et al (2016) Modelling of a population of heat pumps as a source of load in the Great Britain power system. In: Proceedings of international conference on smart systems and technologies, Osijek, Croatia, 12-14 October 2016, 5 pp

[13] Lee SJ, Kim JH, Kim CH et al (2016) Coordinated control algorithm for distributed battery energy storage systems for mitigating voltage and frequency deviations. IEEE Trans Smart Grid 7(3):1713-1723

[14] Sami SS, Meng C, Jianzhong W (2016) Modelling and control of multi-type grid-scale energy storage for power system frequency response. In: Proceedings of IEEE international power electronics and motion control conference, Hefei, China, 22-26 May 2016, 5 pp

[15] NETS security and quality of supply standard (2017) Accessed February 2017

[16] plc NG (2017) Frequency response services in the GB power system: general descriptions. Accessed September 2017

[17] Ekanayake NJAJ (2017) Renewable energy engineering. Cambridge University Press, Cambridge

[18] Grid N (2016) System operability framework 2016. National Grid

[19] Sami SS (2017) Virtual energy storage for frequency and voltage control. Dissertation, Cardiff University

[20] National Grid (2016) System operability framework. http:// www2.nationalgrid.com/UK/Industry-information/Future-of-
Energy/System-Operability-Framework/. Accessed 15 February 2017

[21] Commission UGI (2016) Smart power

[22] plc" NG (2017) Firm frequency response-FAQ. http://www2. nationalgrid.com/UK/Services/Balancing-services/Frequencyresponse/Firm-Frequency-Response/

[23] Firm Frequency Response-Services Reports (2017) National grid. Accessed June 2017

[24] Obaid ZA (2018) Control of frequency in future power systems. Dissertation, Cardiff University

[25] Grid N (2014) Enhanced frequency control capability (EFCC). https://www.ofgem.gov.uk/ofgem-publications/91433/ elecnicfullsubmissionproformaefccresubmission.pdf. Accessed 15 February 2017

[26] Obaid ZA, Cipcigan LM, Muhssin MT (2016) Fuzzy hierarchal approach-based optimal frequency control in the Great Britain power system. Electric Power Syst Res 141:529-537

[27] Mazin T, Muhssin LMC, Obaid ZA et al (2017) A novel adaptive deadbeat- based control for load frequency control of low inertia system in interconnected zones north and south of Scotland. Int J Electric Power Energy Syst 89:52-61

[28] Strbac G, Shakoor A, Black M et al (2007) Impact of wind generation on the operation and development of the UK electricity systems. Electric Power Syst Res 77(9):1214-1227

[29] Obaid ZA, Cipcigan L, Muhsin MT (2015) Analysis of the Great Britain's power system with electric vehicles and storage systems. In: Proceedings of international conference on intelligent system application to power systems, Porto, Portugal, 11-16 September 2015, 6 pp

[30] Grid N (2015) Future energy scenarios. http://fes.nationalgrid. $\mathrm{com} /$

[31] Mu Y, Wu J, Ekanayake J et al (2013) Primary frequency response from electric vehicles in the Great Britain power system. IEEE Trans Smart Grid 4(2):1142-1150

[32] Murrell W, Ran L, Wang J (2014) Modelling UK power system frequency response with increasing wind penetration. In: Proceedings of IEEE innovative smart grid technologies-Asia, Kuala Lumpur, Malaysia, 20-23 May 2014, 6 pp

[33] Elizondo MA, Kalsi K, Calderon CM et al (2015) Frequency responsive demand in U.S. western power system model. In: Proceedings of IEEE power \& energy society general meeting, Denver, USA, 26-30 July 2015, 5 pp

[34] Kalsi JHK, Fuller J, Marinovici LD et al (2015) Loads as a resource frequency responsive demand. Prepared for the U.S. Department of Energy under Contract DE-AC05-76RL01830, Pacific Northwest National Laboratory Richland, Washington 99352

[35] Kalsi KJL, Marinovici LD, Elizondo M et al (2014) Loads as a resource frequency responsive demand. Prepared for the U.S. Department of Energy under Contract DE-AC05-76RL01830, Pacific Northwest National Laboratory Richland, Washington 99352

[36] Wang C, Wu J, Ekanayake J et al (2017) Smart electricity distribution networks. CRC Press, Boca Raton

[37] Li B, Shen J, Wang X et al (2016) From controllable loads to generalized demand-side resources: a review on developments of demand-side resources. Renew Sustain Energy Rev 53:936-944

[38] Paterakis NG, Erdinç O, Catalão JP (2017) An overview of demand response: key-elements and international experience. Renew Sustain Energy Rev 69:871-891

[39] Western Power Distribution (2015) Project FALCON: commercial trials final report

[40] Strbac G (2008) Demand side management: benefits and challenges. Energy Policy 36(12):4419-4426 
[41] Cheng M, Wu J, Galsworthy SJ et al (2016) Power system frequency response from the control of bitumen tanks. IEEE Trans Power Syst 31(3):1769-1778

[42] Power Responsive (2016) Demand side flexibility annual report

[43] Energyst (2015) Demand side response report

[44] Energy (2012) Demand side response in the non-domestic sector. Prepared for Ofgem

[45] Cheng M, Wu J, Ekanayake J et al (2013) Primary frequency response in the Great Britain power system from dynamically controlled refrigerators. In: Proceedings of international conference and exhibition on electricity distribution, Stockholm, Sweden, 10-13 June 213,4 pp

[46] Short JA, Infield DG, Freris LL (2007) Stabilization of grid frequency through dynamic demand control. IEEE Trans Power Syst 22(3):1284-1293

[47] Muhssin MT, Cipcigan LM, Jenkins N et al (2016) Modelling of a population of heat pumps as a source of load in the Great Britain power system. In: Proceedings of smart systems and technologies, Osijek, Croatia, 12-14 October 2016, 5 pp

[48] Koch S, Zima M, Andersson G (2009) Active coordination of thermal household appliances for load management purposes. IFAC Proc Vol 42(9):149-154

[49] Lu N (2012) An evaluation of the HVAC load potential for providing load balancing service. IEEE Trans Smart Grid 3(3):1263-1270

[50] Cheng M, Wu J, Galsworthy SJ et al (2017) Performance of industrial melting pots in the provision of dynamic frequency response in the Great Britain power system. Appl Energy 201:245-256

[51] Cheng M, Wu J, Galsworthy S et al (2014) Availability of load to provide frequency response in the Great Britain power system. In: Proceedings of power systems computation conference, Wroclaw, Poland, 18-22 August 2014, 7 pp

[52] Vrettos E, Mathieu JL, Andersson G (2014) Demand response with moving horizon estimation of individual thermostatic load states from aggregate power measurements. In: Proceedings of American control conference, Portland, USA, 4-6 June 2014, 8 pp

[53] Mathew AM, Menon R (2015) Assessment of demand response capability with thermostatic loads in residential sector. In: Proceedings of international conference on power, instrumentation, control and computing, Thrissur, India, 9-11 December 2015, $5 \mathrm{pp}$

[54] Mathieu JL, Kamgarpour M, Lygeros J et al (2015) Arbitraging intraday wholesale energy market prices with aggregations of thermostatic loads. IEEE Trans Power Syst 30(2):763-772

[55] Tindemans SH, Trovato V, Strbac G (2015) Decentralized control of thermostatic loads for flexible demand response. IEEE Trans Control Syst Technol 23(5):1685-1700

[56] Trovato V, Sanz IM, Chaudhuri B et al (2016) Advanced control of thermostatic loads for rapid frequency response in Great Britain. IEEE Trans Power Syst 32(3):2106-2117

[57] Trovato V, Teng F, Strbac G (2016) Value of thermostatic loads in future low-carbon Great Britain system. In: Proceedings of power systems computation conference, Genoa, Italy, 20-24 June 2016, 7 pp

[58] Trovato V, Tindemans SH, Strbac G (2016) Leaky storage model for optimal multi-service allocation of thermostatic loads. IET Gen Transm Distrib 10(3):585-593

[59] Trovato V, Martinez-Sanz I, Chaudhuri B et al (2017) Advanced control of thermostatic loads for rapid frequency response in Great Britain. In: Proceedings of IEEE Manchester PowerTech, Manchester, UK, 18-22 June 2017, 1 pp

[60] Latif A, Khan S, Palensky P et al (2016) Co-simulation based platform for thermostatically controlled loads as a frequency reserve. In: Proceedings of workshop on modeling and simulation of cyber-physical energy systems, Vienna, Austria, 11 April 2016, 6 pp

[61] Trovato V, Teng F, Strbac G (2017) Role and benefits of flexible thermostatically controlled loads in future low-carbon systems. IEEE Trans Smart Grid. https://doi.org/10.1109/TSG. 2017.2679133

[62] Trovato V, Tindemans SH, Strbac G (2013) Demand response contribution to effective inertia for system security in the GB 2020 gone green scenario. In: Proceedings of IEEE PES ISGT Europe, Lyngby, Denmark, 6-9 October 2013, 5 pp

[63] Christian MWZ, Lian J, Karanjit K (2014) A hierarchical framework for demand-side frequency control. In: Proceedings of the American control conference, Portland, USA, 4-6 June 2014, $6 \mathrm{pp}$

[64] Xu Z, Diao R, Lu S et al (2014) Modeling of electric water heaters for demand response: a baseline PDE model. IEEE Trans Smart Grid 5(5):2203-2210

[65] Cooper D, Cronje W (2016) Autonomous water heater control for load regulation on smart grids. In: Proceedings of IEEE international energy conference, Leuven, Belgium, 4-8 April 2016, $6 \mathrm{pp}$

[66] Masuta T, Yokoyama A (2012) Supplementary load frequency control by use of a number of both electric vehicles and heat pump water heaters. IEEE Trans Smart Grid 3(3):1253-1262

[67] Kim YJ, Fuentes E, Norford LK (2016) Experimental study of grid frequency regulation ancillary service of a variable speed heat pump. IEEE Trans Power Syst 31(4):3090-3099

[68] Kim YJ, Norford LK, Kirtley JL (2015) Modeling and analysis of a variable speed heat pump for frequency regulation through direct load control. IEEE Trans Power Syst 30(1):397-408

[69] Power H (2017) Water heaters. Accessed 16 October 2017

[70] Youngjin K (2016) Experimental study of grid frequency regulation ancillary service of a variable speed heat pump. In: Proceedings of IEEE PESGM, Boston, USA, 17-21 July 2016, $1 \mathrm{pp}$

[71] Vrettos E, Koch S, Andersson G (2012) Load frequency control by aggregations of thermally stratified electric water heaters. In: Proceedings of IEEE PES innovative smart grid technologies Europe, Berlin, Germany, 14-17 October 2012, 8 pp

[72] Masuta T, Yokoyama A, Tada Y (2011) Modeling of a number of heat pump water heaters as control equipment for load frequency control in power systems. In: Proceedings of IEEE Trondheim powertech, Trondheim, Norway, 19-23 June 2011, $7 \mathrm{pp}$

[73] Obaid ZA, Cipcigan L, Muhssin MT (2017) Design of a hybrid fuzzy/Markov chain-based hierarchal demand-side frequency control. In; Proceedings of IEEE PES GM, Chicago, USA, 16-20 July 2017, 5 pp

[74] Muhssin MT (2018) Adaptive control and dynamic demand response for the sabilization of the gid fequency. Dissertation, Cardiff University

[75] Kalsi JLK, Marinovici LD, Elizondo M et al (2014) Loads as a resource frequency responsive demand. U.S. Department of Energy under Contract DE-AC05-76RL01830, Pacific Northwest National Laboratory Richland, Washington 99352

[76] Williams T, Kalsi K, Elizondo M et al (2016) Control and coordination of frequency responsive residential water heaters. In: Proceedings of IEEE power and energy society general meeting, Boston, USA, 17-21 July 2016, 5 pp

[77] Karfopoulos EL, Hatziargyriou ND (2013) A multi-agent system for controlled charging of a large population of electric vehicles. IEEE Trans Power Syst 28(2):1196-1204

[78] Qazi HW, Flynn D, Rather ZH (2016) Impact of electric vehicle load response variation on frequency stability. In: Proceedings of IEEE PES innovative smart grid technologies 
conference Europe, Ljubljana, Slovenia, 9-12 October 2016, 6 pp

[79] Moghadam MRV, Zhang R, Ma RTB (2016) Distributed frequency control via randomized response of electric vehicles in power grid. IEEE Trans Sustain Energy 7(1):312-324

[80] Li J, Xiong R, Yang Q et al (2016) Design/test of a hybrid energy storage system for primary frequency control using a dynamic droop method in an isolated microgrid power system. Appl Energy 201:257-269

[81] Grid N (2017) Future energy scenario. http://fes.nationalgrid. com/media/1253/final-fes-2017-updated-interactive-pdf-44amended.pdf. Accessed 16 October 2017

[82] Energy C (2017) Enel buys up lucrative battery storage project for $£ 17$ million. Accessed 16 October 2017

[83] Kim Y-J, Del-Rosario-Calaf G, Norford LK (2017) Analysis and experimental implementation of grid frequency regulation using behind-the-meter batteries compensating for fast load demand variations. IEEE Trans Power Syst 32(1):484-498

[84] Iversen EB, Morales JM, Madsen H (2014) Optimal charging of an electric vehicle using a Markov decision process. Appl Energy 123:1-12

[85] Song J, Krishnamurthy V, Kwasinski A et al (2013) Development of a Markov-chain-based energy storage model for power supply availability assessment of photovoltaic generation plants. IEEE Trans Sustain Energy 4(2):491-500

[86] Tang Y, Zhong J, Bollen M (2016) Aggregated optimal charging and vehicle-to-grid control for electric vehicles under large electric vehicle population. IET Gen Transm Distrib 10(8):2012-2018

[87] Alhejaj SM, Gonzalez-Longatt FM (2016) Impact of inertia emulation control of grid-scale BESS on power system frequency response. In: Proceedings of international conference for students on applied engineering, Newcastle upon Tyne, UK, 20-21 October 2016, 5 pp

[88] Hatziargyriou N (2014) MicroGrids. Wiley-IEEE press, USA

[89] Khooban MH, Dragicevic T, Blaabjerg F et al (2018) Shipboard microgrids: a novel approach to load frequency control. IEEE Trans Sustain Energy 9(2):843-852

[90] Khooban MH, Niknam T, Shasadeghi M et al (2018) Load frequency control in microgrids based on a stochastic noninteger controller. IEEE Trans Sustain Energy 9(2):853-861

[91] Mohammadi FD, Vanashi HK, Feliachi A (2018) State-space modeling, analysis, and distributed secondary frequency control of isolated microgrids. IEEE Trans Energy Convers 33(1): $155-165$

[92] Dehkordi NM, Sadati N, Hamzeh M (2017) Fully distributed cooperative secondary frequency and voltage control of islanded microgrids. IEEE Trans Energy Convers 32(2):675-685

[93] Pilloni A, Pisano A, Usai E (2018) Robust finite-time frequency and voltage restoration of inverter-based microgrids via slidingmode cooperative control. IEEE Trans Ind Electron 65(1):907-917

[94] Lund P (2007) The danish cell project-part 1: background and general approach. In: Proceedings of power engineering society general meeting, Tampa, USA, 24-28 June 2007, 6 pp

[95] Ekanayake JB, Jenkins N, Liyanage K et al (2012) Smart grid: technology and applications. Wiley, New York

[96] Pudjianto D, Ramsay C, Strbac G (2007) Virtual power plant and system integration of distributed energy resources. IET Renew Power Gen 1(1):10-16

[97] Wu Z, Gao DW, Zhang H et al (2017) Coordinated control strategy of battery energy storage system and PMSG-WTG to enhance system frequency regulation capability. IEEE Trans Sustain Energy 8(3):1330-1343
[98] Persson M, Chen P (2017) Frequency control by variable speed wind turbines in islanded power systems with various generation mix. IET Renew Power Gen 11(8):1101-1109

[99] Wilches-Bernal F, Chow JH, Sanchez-Gasca JJ (2016) A fundamental study of applying wind turbines for power system frequency control. IEEE Trans Power Syst 31(2):1496-1505

[100] Zhang Y, Tomsovic K, Djouadi SM et al (2017) Hybrid controller for wind turbine generators to ensure adequate frequency response in power networks. IEEE J Emerg Select Top Circuits Syst 7(3):359-370

[101] Ashouri-Zadeh A, Toulabi M, Ranjbar AM (2016) Coordinated design of fuzzy-based speed controller and auxiliary controllers in a variable speed wind turbine to enhance frequency control. IET Renew Power Gen 10(9):1298-1308

[102] Yao J, Yu M, Gao W et al (2017) Frequency regulation control strategy for PMSG wind-power generation system with flywheel energy storage unit. IET Renew Power Gen 11(8):1082-1093

[103] Wang J, Zhang H, Zhou Y (2017) Intelligent under frequency and under voltage load shedding method based on the active participation of smart appliances. IEEE Trans Smart Grid $8(1): 353-361$

[104] Rudez U, Mihalic R (2016) WAMS-based underfrequency load shedding with short-term frequency prediction. IEEE Trans Power Deliv 31(4):1912-1920

[105] Coelho VN, Coelho IM, Coelho BN et al (2016) A communitarian microgrid storage planning system inside the scope of a smart city. Appl Energy 201:371-381

[106] Jin X, Mu Y, Jia H et al (2016) Dynamic economic dispatch of a hybrid energy microgrid considering building based virtual energy storage system. Appl Energy 194:386-398

[107] Parra D, Norman SA, Walker GS et al (2016) Optimum community energy storage system for demand load shifting. Appl Energy 174:130-143

[108] Lombardi P, Schwabe F (2017) Sharing economy as a new business model for energy storage systems. Appl Energy 188:485-496

[109] Morstyn T, Momayyezan M, Hredzak B et al (2016) Distributed control for state-of-charge balancing between the modules of a reconfigurable battery energy storage system. IEEE Trans Power Electron 31(11):7986-7995

[110] Cai H, Hu GQ (2016) Distributed control scheme for packagelevel state-of-charge balancing of grid-connected battery energy storage system. IEEE Trans Ind Inform 12(5):1919-1929

[111] Grid N (2014) Electricity ten year statement. UK Electricity Transmission, London

[112] Moeini A, Kamwa I, Brunelle P et al (2015) Open data IEEE test systems implemented in SimPowerSystems for education and research in power grid dynamics and control. In: Proceedings of international universities power engineering conference, Stoke on Trent, UK, 1-4 September 2015, 6 pp

[113] Hiskens RRAI (2015) IEEE PES task gorce on benchmark systems for stability controls-technical report

[114] Vowles MGAD (2014) Simplified 14-generator model of the South East Australian power system. Dissertation, The University of Adelaide

Zeyad Assi OBAID received the B.Sc. degree in Control and Systems Engineering from University of Technology, Iraq, in 2006 and M.Sc. in Control and Automation Engineering from University Putra Malaysia (UPM), Malaysia, in 2010. He received the Ph.D. degree in Electrical and Electronic Engineering from Cardiff University, UK, in April 2018. His main research interests include intelligent control and frequency control in power systems. 
Liana M. CIPCIGAN is a Reader at Cardiff University's School of Engineering, Centre for Integrated Renewable Energy Generation and Supply. Her research experience covers power system analysis and control, smart grids, virtual power plants and DER integration in distribution networks. She is leading the research of electric vehicles integration and control in distribution networks. She has collaborated widely with industry, more recently during her secondment at National Grid under Royal Academy of Engineering industrial fellowship, working in the Energy Insights department responsible for the Future Energy Scenarios. She has published around 100 scientific papers, book chapters and conference papers.

Lahieb ABRAHIM has a B.Sc. M. Sc., and Ph.D. in Electrical Engineering from School of Engineering, South Wales University,
UK. He is working in the same University. His research interests include design and optimisation in power systems.

Mazin T. MUHSSIN received the B.Sc. degree in Control and Systems Engineering from University of Technology, Iraq, in 2006 and the M.Sc. degree in Control and Automation Engineering from University Putra Malaysia (UPM), Malaysia, in 2010, and the Ph.D. degree in Electrical and Electronic Engineering from Cardiff University, UK. He was engaged in the EPSRC project "Ebbs and Flows of Energy Systems". His main research interests include smart grids, flexible demand control, balancing services and dynamic demand response. 